\title{
Variation of iodine status during pregnancy and its associations with thyroid function in women from Rio de Janeiro, Brazil
}

\author{
Carolina Martins Corcino*, Tatiana Martins Benvenuto Louro Berbara,
} Débora Ayres Saraiva, Nathalie Anne de Oliveira e Silva de Morais, Annie Schtscherbyna, Larissa Nascimento Gertrudes, Patrícia de Fátima dos Santos Teixeira and Mario Vaisman Department of Endocrinology, Hospital Universitário Clementino Fraga Filho, Universidade Federal do Rio de Janeiro, Rua Prof. Rodolpho Paulo Rocco 255, $9^{\circ}$ andar, sala 9E23, Rio de Janeiro, RJ 21941-913, Brazil

Submitted 13 September 2018: Final revision received 11 January 2019: Accepted 18 January 2019: First published online 8 March 2019

\begin{abstract}
Objective: To assess iodine status and its effects on maternal thyroid function throughout pregnancy.

Design: In the present prospective cohort study, three urinary samples were requested for urinary iodine concentration (UIC) determinations in both the first and third gestational trimesters. Serum thyrotropin (TSH) and free thyroxine (FT 4 ) were analysed in both trimesters and thyroid antibodies were assessed once.

Setting: Rio de Janeiro, Brazil.

Participants: First-trimester pregnant women ( $n$ 243), of whom 100 were reevaluated during the third trimester.

Results: Iodine sufficiency was found in the studied population (median $\mathrm{UIC}=216.7 \mu \mathrm{g} / \mathrm{l})$. The first- and third-trimester median UIC was 221.0 and $208.0 \mu \mathrm{g} / \mathrm{l}$, respectively. TSH levels (mean (SD)) were higher in the third trimester (1.08 (0.67) v. $1.67(0.86)$ mIU/l; $P<0.001)$, while $\mathrm{FT}_{4}$ levels decreased significantly $(1.18(0.16) v .0 .88(0.12) \mathrm{ng} / \mathrm{dl} ; P<0.001)$, regardless the presence of iodine deficiency (UIC $<150 \mu \mathrm{g} / \mathrm{l}$ ) or circulating thyroid antibodies. UIC correlated $(\beta ; 95 \% \mathrm{CI})$ independently and negatively with age $(-0 \cdot 43 ;-0 \cdot 71$, $-0 \cdot 17)$ and positively with multiparity $(0 \cdot 15 ; 0 \cdot 02,0 \cdot 28)$ and BMI $(0 \cdot 25 ; 0 \cdot 00,0 \cdot 50)$. Furthermore, median UIC per pregnant woman tended to correlate positively with TSH $(0 \cdot 07 ;-0 \cdot 01,0 \cdot 14)$. Women with median UIC $\geq 250 \mu \mathrm{g} / 1$ and at least one sample $\geq 500 \mu \mathrm{g} / \mathrm{l}$ throughout pregnancy had a higher risk of subclinical hypothyroidism (OR $=6 \cdot 6 ; 95 \%$ CI $1 \cdot 2,37 \cdot 4)$.

Conclusions: In this cohort with adequate iodine status during pregnancy, excessive UIC was associated with an increased risk of subclinical hypothyroidism.
\end{abstract}

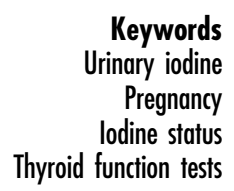

Iodine is an essential micronutrient for thyroid hormone synthesis. Its deficiency during pregnancy, even when mild to moderate, may lead to unfavourable obstetric outcomes and impaired fetal neurocognitive development ${ }^{(1-3)}$.

Recently, insufficient iodine intake during gestation has been reported even in countries adopting prophylactic programmes to promote iodized salt consumption ${ }^{(4-6)}$. In this context, total-body iodine stores, as reflected by urinary iodine concentrations (UIC), tend to decline gradually from the first to the third trimester of pregnancy, resulting in impaired maternal and fetal thyroid hormone synthesis $^{(7)}$. As a result, the latest guidelines from the American Thyroid Association and the Endocrine Society endorse systematic administration of iodine supplements for women who are pregnant or planning pregnancy in most regions, including the $\mathrm{USA}^{(8,9)}$. The same conduct is recommended by leading health authorities in Europe and Australia $^{(10,11)}$. However, it is unclear whether this policy should be implemented universally.

On the other hand, excessive iodine intake during pregnancy has been related to maternal and fetal thyroid dysfunction $^{(12,13)}$. Iodine supplementation in iodinesufficient regions may lead to higher maternal and neonatal thyrotropin (TSH) levels in addition to lower maternal free thyroxine $\left(\mathrm{FT}_{4}\right)$ levels ${ }^{(14,15)}$. Furthermore, even in areas with mild to moderate iodine deficiency, no interventional study has convincingly shown a benefit with respect to obstetric outcomes when iodine supplementation is given ${ }^{(3)}$. 
Lately, adequate iodine status in healthy first-trimester pregnant women living in Rio de Janeiro, a coastal state of Brazil, has been observed ${ }^{(16)}$. These results differed from those reported by Ferreira et al. and Mioto et al., who found insufficient UIC in pregnant women from noncoastal areas of the state of São Paulo ${ }^{(17,18)}$. Additionally, no longitudinal studies concerning gestationally related UIC changes and thyroid parameters have been carried out in the country to date.

The aim of the present study was to prospectively evaluate iodine nutritional status and its association with maternal thyroid function from the first to the third trimester in a sample of pregnant women in the state of Rio de Janeiro, Brazil.

\section{Methods}

\section{Study design and participants}

The present study was a prospective observational study from an ongoing cohort of healthy pregnant women. Participants were consecutively recruited between September 2014 and February 2017 while they were attending a routine antenatal appointment at four different public primary care units in the urban area of the state of Rio de Janeiro. We included 243 women aged 18 to 35 years old in their first trimester of pregnancy. A subgroup of 100 women was tested again in the third trimester, which provided us with additional data concerning iodine status and serum $\mathrm{TSH} / \mathrm{FT}_{4}$ from the last trimester of pregnancy. UIC and serum analysis in the third trimester could not be assessed in 143 women since nineteen were referred to other specialists due to abnormal laboratory tests, twelve had miscarriages and one went into very premature labour. Furthermore, twenty-one declined to participate and two were referred to different prenatal units. The remaining women in the group that was not re-evaluated were lost from follow-up.

Patients with known thyroid or any other chronic diseases, multifetal pregnancies and those taking iodinecontaining supplements at enrolment were excluded. Thereafter, pregnant women received the usual obstetric follow-up examination, and we did not interfere in the prescribed dietary recommendations, medications or vitamin supplements. The study was approved by the local ethics committee and written informed consent was obtained from each of the participants.

\section{Clinical and laboratory evaluation}

After medical history and physical examination, BMI $\left(\mathrm{kg} / \mathrm{m}^{2}\right)$ was calculated as weight (in kilograms) divided by the square of height (in metres). Gestational age was calculated from the first day of the last normal menstrual period, and gestational ages $\leq 12$ and $\geq 28$ weeks comprised the first and third trimesters of pregnancy, respectively.
Blood samples were analysed for the concentrations of TSH, $\mathrm{FT}_{4}$ and antithyroid antibodies (thyroperoxidase antibody (TPOAb) and thyroglobulin antibody (TgAb)) in the first trimester. Serum TSH and $\mathrm{FT}_{4}$ levels were also reassessed in the third trimester.

In both trimesters, pregnant women were asked to collect three casual urine samples on different days and UIC was measured. They were also instructed to bring approximately $30 \mathrm{~g}$ of table salt from their homes so that iodine concentration could be determined.

\section{Assays}

Serum TSH, FT 4 , TPOAb and TgAb levels were determined using an electrochemiluminescence immunoassay (Roche Modular Analytics ${ }^{\circledR}$ E170). Levels of various parameters from pregnant women were compared with laboratory reference ranges for healthy adults: (i) TSH, 0.4 to $4.3 \mathrm{mIU} / \mathrm{l}$; (ii) $\mathrm{FT}_{4}, 0.7$ to $1.9 \mathrm{ng} / \mathrm{dl}$; (iii) $\mathrm{TPOAb},<34 \mathrm{IU} / \mathrm{ml}$; and (iv) $\mathrm{TgAb},<115 \mathrm{IU} / \mathrm{ml}$. Intra- and inter-assay CV were respectively 7.2 and $3.0 \%$ for TSH; 2.8 and $2.9 \%$ for $\mathrm{FT}_{4} ; 6.3$ and $7.0 \%$ for TPOAb; and 4.9 and $6.3 \%$ for TgAb.

We applied the new criteria proposed by the American Thyroid Association to define subclinical hypothyroidism $(\mathrm{SCH})$ as serum $\mathrm{TSH} \geq 3.8 \mathrm{mIU} / \mathrm{l}$ accompanied by a normal serum $\mathrm{FT}_{4}$ concentration in both trimesters ${ }^{(8)}$.

UIC was determined using inductively coupled plasma mass spectrometry (Spectroquant ${ }^{\circledR}$ Iodine Test; Merck KGaA, Germany). The manufacturer's reference range was 26 to $705 \mu \mathrm{g} / \mathrm{l}$. Iodine status was classified according to the WHO/UNICEF/International Council for Control of Iodine Deficiency Disorders guidelines: (i) severely insufficient, $<50 \mu \mathrm{g} / \mathrm{l}$; (ii) mild-to-moderate insufficient, $50-149 \mu \mathrm{g} / \mathrm{l}$; (iii) sufficient, 150-249 $\mu \mathrm{g} / \mathrm{l}$; (iv) more than adequate, 250-499 $\mu \mathrm{g} / \mathrm{l}$; and (v) excessive, $\geq 500 \mu \mathrm{g} / \mathrm{l}^{(19)}$.

The domestic salt samples were analysed for the iodine content using the titration method, following the procedure of the Adolfo Lutz Institute Analytical Standards ${ }^{(20)}$. The examinations were performed in triplicate by an experienced chemist, and concentrations between 15 and $45 \mathrm{mg} / \mathrm{kg}$ were classified as appropriate in accordance with the Brazilian government recommendations ${ }^{(21)}$.

\section{Statistical analysis}

Statistical analyses were performed using the statistical software package IBM SPSS Statistics for Windows version 21.0.

The Kolmogorov-Smirnov test showed that no continuous variable had a normal distribution data in the studied population. Categorical variables were described as frequencies and compared between groups using the $\chi^{2}$ or Fisher's exact test. Continuous variables were described as mean with standard deviation or median with interquartile range and compared between groups by the Mann-Whitney test.

The Wilcoxon test was employed for inter-trimester comparisons of biochemical parameters in the same 
Table 1 Distribution of urinary iodine concentration (UIC) considering all collected samples and according to trimesterspecific time of pregnancy in women from the state of Rio de Janeiro, Brazil, September 2014-February 2017

\begin{tabular}{|c|c|c|c|c|c|c|c|c|}
\hline & \multicolumn{6}{|c|}{ Excluding women taking iodine supplements } & \multicolumn{2}{|c|}{ Women taking iodine supplements } \\
\hline & \multicolumn{2}{|c|}{ All } & \multicolumn{2}{|c|}{ First trimester } & \multicolumn{2}{|c|}{ Third trimester } & \multicolumn{2}{|c|}{ Third trimester } \\
\hline No. of urine samples & \multicolumn{2}{|c|}{856} & \multicolumn{2}{|c|}{629} & \multicolumn{2}{|c|}{227} & \multicolumn{2}{|c|}{40} \\
\hline Gestational weeks & \multirow{2}{*}{\multicolumn{2}{|c|}{$\mathrm{N} / \mathrm{A}$}} & \multirow{2}{*}{\multicolumn{2}{|c|}{$\begin{array}{r}9 \cdot 0 \\
1 \cdot 8\end{array}$}} & \multirow{2}{*}{\multicolumn{2}{|c|}{$\begin{array}{c}32.9 \\
3.1\end{array}$}} & \multirow{2}{*}{\multicolumn{2}{|c|}{$\begin{array}{c}32.6 \\
2.9\end{array}$}} \\
\hline SD & & & & & & & & \\
\hline \multirow{3}{*}{$\begin{array}{l}\text { Median UIC }(\mu \mathrm{g} / \mathrm{I}) \\
\text { IQR }\end{array}$} & \multirow{2}{*}{\multicolumn{2}{|c|}{$\begin{array}{c}216 \cdot 7 \\
147 \cdot 8-314 \cdot 7\end{array}$}} & \multirow{2}{*}{\multicolumn{2}{|c|}{$\begin{array}{c}221 \cdot 0 \\
149 \cdot 6-312.8\end{array}$}} & \multirow{2}{*}{\multicolumn{2}{|c|}{$\begin{array}{c}208 \cdot 0 \\
143 \cdot 0-323 \cdot 6\end{array}$}} & \multirow{2}{*}{\multicolumn{2}{|c|}{$\begin{array}{c}262 \cdot 1 \\
139 \cdot 2-370 \cdot 6\end{array}$}} \\
\hline & & & & & & & & \\
\hline & $\%$ & $n$ & $\%$ & $n$ & $\%$ & $n$ & $\%$ & $n$ \\
\hline \multicolumn{9}{|l|}{ UIC category } \\
\hline$<50 \mu \mathrm{g} / \mathrm{l}$ & $2 \cdot 0$ & 17 & 1.9 & 12 & $2 \cdot 2$ & 5 & $5 \cdot 0$ & 2 \\
\hline $50-149 \mu \mathrm{g} / \mathrm{l}$ & 23.9 & 205 & $23 \cdot 2$ & 146 & $26 \cdot 0$ & 59 & 22.5 & 9 \\
\hline $150-249 \mu \mathrm{g} / \mathrm{l}$ & 33.3 & 285 & $34 \cdot 0$ & 214 & $31 \cdot 3$ & 71 & $22 \cdot 5$ & 9 \\
\hline $250-499 \mu \mathrm{g} / \mathrm{l}$ & 34.3 & 294 & 34.7 & 218 & 33.5 & 76 & 32.5 & 13 \\
\hline$\geq 500 \mu \mathrm{g} / \mathrm{l}$ & $6 \cdot 4$ & 55 & $6 \cdot 2$ & 39 & $7 \cdot 0$ & 16 & $17 \cdot 5$ & 7 \\
\hline
\end{tabular}

IQR, interquartile range (25th-75th percentile); N/A, not applicable.

participants in the study cohort. Stratified analysis by the presence of iodine insufficiency, iodine excess and positive thyroid antibodies were also performed to test the variations of thyroid hormones between the first and third trimesters.

Multivariate linear regression was applied to detect which variables were independently associated with UIC levels. The variables included in the model assessing all urinary samples included age, iodine concentration in table salt, gestational age, BMI at study entry, TSH and $\mathrm{FT}_{4}$ at the time of urine collection, smoking habits, multiparity ( $\geq 3$ labours) and positivity for serum thyroid antibodies.

Multivariate linear regression was also applied to detect which variables were independently associated with median UIC levels per woman during pregnancy. Again, the variables included in the model assessing all urinary samples were age, iodine concentration in table salt, BMI at study entry, median TSH and $\mathrm{FT}_{4}$ during pregnancy, smoking habits, multiparity and positivity for serum thyroid antibodies. This analysis using the same model was thereafter reapplied excluding those women who were using levothyroxine or iodine supplements.

Finally, we assessed which confounding variables might be independently related to $\mathrm{SCH}$ diagnosis during pregnancy. For this purpose, a binary logistic regression was applied. The included variables in this model were age, BMI, multiparity, smoking habits, iodine supplement use, insufficient iodine content in table salt, and any UIC $\geq$ $500 \mu \mathrm{g} / \mathrm{l}$ associated with median UIC $\geq 250 \mu \mathrm{g} / \mathrm{l}$ during pregnancy. As a second step, we added positive circulating thyroid antibodies to the model.

\section{Results}

A group of 243 women in the first trimester of pregnancy were included in the study. Their mean (SD) age and BMI at enrolment were $26.5(4.9)$ years and $25 \cdot 0(6.6) \mathrm{kg} / \mathrm{m}^{2}$, respectively. As stated in the 'Methods' section, from this initial group, 100 women were re-evaluated in the third trimester, providing us with additional data concerning iodine status and serum $\mathrm{TSH} / \mathrm{FT}_{4}$ during this last trimester of pregnancy. Women who completed the study ( $n$ 100) did not differ from those who were lost from follow-up regarding mean (SD) UIC (237.5 (105.1) v. $250 \cdot 3(106 \cdot 8) \mu \mathrm{g} / \mathrm{l}$, respectively; $P=0.35)$ and $\mathrm{BMI}(25 \cdot 2(5 \cdot 3) v .25 \cdot 6(5 \cdot 2)$ $\mathrm{kg} / \mathrm{m}^{2}$, respectively; $\left.P=0.53\right)$. The distribution of multiparous women was also the same among the two groups $(P>0 \cdot 10)$.

A total of 896 urine samples were analysed from the whole population included in the study. Of these women, fourteen received prescription iodine supplements between the first and the third trimester and were examined separately (Table 1). The results regarding the analysis of the salt samples have been previously reported by our group, and most of the samples contained adequate iodine levels ${ }^{(16)}$.

\section{Iodine status and gestational changes of urinary iodine concentration and thyroid function tests}

Iodine status from the studied population was determined in 856 urine samples after excluding the group taking iodine supplements. The overall median UIC was $216 \cdot 7 \mu \mathrm{g} / \mathrm{l}$, which is considered adequate according to the WHO criteria ${ }^{(19)}$. Insufficient UIC $(<150 \mu \mathrm{g} / \mathrm{l})$ was found in $25.9 \%$ of all urine samples, and only $2 \cdot 0 \%$ had severe insufficiency $(<50 \mu \mathrm{g} / \mathrm{l})$. In contrast, UIC above the recommended level $(\geq 250 \mu \mathrm{g} / \mathrm{l})$ was observed in $40.7 \%$ of the samples with $6.4 \%$ showing excessive iodine excretion $(\geq 500 \mu \mathrm{g} / \mathrm{l})$, as shown in Table 1.

Median UIC in the first and third trimesters was 221.0 and $208.0 \mu \mathrm{g} / \mathrm{l}$, respectively. There were no significant differences in the frequencies of normal or inappropriate UIC between the analysed trimesters (Table 1). 
Table 2 Comparisons between urinary iodine concentration (UIC; $n 86)^{\star}$ and thyroid hormones $(n 71) \dagger$ in the first and third trimesters in women from the state of Rio de Janeiro, Brazil, September 2014-February 2017

\begin{tabular}{lcccccrr}
\hline & \multicolumn{2}{c}{ First trimester } & & \multicolumn{2}{c}{ Third trimester } & \\
\cline { 2 - 3 } & Mean & SD & & Mean & SD & $P \ddagger$ \\
\hline UIC $(\mu \mathrm{g} / \mathrm{l})$ & 231.6 & 100.8 & & 245.8 & 108.9 & 0.324 \\
$\mathrm{TSH}(\mathrm{mlU} / \mathrm{l})$ & 1.08 & 0.67 & & 1.67 & 0.86 & $<0.001$ \\
$\mathrm{FT}_{4}(\mathrm{ng} / \mathrm{dl})$ & 1.18 & 0.16 & & 0.88 & 0.12 & $<0.001$ \\
\hline
\end{tabular}

$\mathrm{TSH}$, thyrotropin; FT4, free thyroxine.

${ }^{*}$ After excluding patients under iodine supplementation.

†After excluding patients on levothyroxine use.

$\ddagger$ Wilcoxon test (paired analysis).

As described, fourteen women were taking multivitamin supplements containing $150 \mu \mathrm{g}$ of iodine at the thirdtrimester visit. They provided us with a total of forty urine samples. The median UIC in this group was $\geq 250 \mu \mathrm{g} / \mathrm{l}$ $(262 \cdot 1 \mu \mathrm{g} / \mathrm{l})$, as shown in Table 1 . Their mean thirdtrimester UIC, TSH and $\mathrm{FT}_{4}$ levels were not significantly different from those of women who did not use iodine supplements $(292.5$ v. $245.8 \mu \mathrm{g} / 1, \quad P=0.280 ; 1.76 \quad v$. $1.67 \mathrm{mIU} / 1, P=0.577$; and 0.92 v. $0.88 \mathrm{ng} / \mathrm{dl}, P=0.711$, respectively).

Considering only those women tested in both trimesters, there were no significant differences between their mean (SD) trimester-specific UIC values based on the paired analysis, after excluding patients under iodine supplementation (Table 2).

Mean (SD) TSH levels were higher in the third trimester, while $\mathrm{FT}_{4}$ levels decreased significantly, emphasizing that these kinds of analyses were done after excluding also those patients who initiated levothyroxine during the study (Table 2). These variations remained significant regardless the presence of iodine deficiency (at least one urine sample of the first trimester with UIC $<150 \mu \mathrm{g} / \mathrm{l}$ ) or the presence of positive thyroid antibodies as demonstrated in stratified analysis (Table 3).

\section{Correlations between urinary iodine concentration, clinical parameters and thyroid function}

A negative and independent correlation was found between UIC from all collected samples and women's age as demonstrated in the multivariate analysis (Table 4). These findings were confirmed by performing analysis of the median UIC of each participant, and even after excluding those who collected urinary samples while using iodine supplements and those who initiated levothyroxine for SCH (Table 5). In contrast, UIC was positively related to multiparity and BMI (Tables 4 and 5). Furthermore, median UIC per pregnant woman tended to be positively correlated with serum TSH after excluding those on levothyroxine or using iodine supplementation (Table 5).

\section{Associations between urinary iodine concentration and subclinical bypothyroidism diagnosis during pregnancy}

From the 243 pregnant women, twelve received a $\mathrm{SCH}$ diagnosis (eleven were diagnosed in the first trimester and one later).

Excessive UIC $(\geq 500 \mu \mathrm{g} / \mathrm{l})$ in any of the collected samples was associated with SCH diagnosis during pregnancy (as shown in Table 6) and confirmed in multivariate analysis (Table 7). The median UIC in patients with $\mathrm{SCH}$ was $\geq 250 \mu \mathrm{g} / \mathrm{l}$ despite the absence of statistical significance when comparing results with euthyroid pregnant women (Table 6). Age was lower among SCH participants. Furthermore, circulating thyroid antibodies and smoking habits were more frequent in this subgroup (Table 6).

Table 3 Stratified analysis by the presence of iodine insufficiency and positive thyroid antibodies to test the variations of thyroid hormones from the first to the third trimester in women from the state of Rio de Janeiro, Brazil, September 2014-February 2017

\begin{tabular}{|c|c|c|c|c|c|}
\hline & \multicolumn{2}{|c|}{ First trimester } & \multicolumn{2}{|c|}{ Third trimester } & \multirow[b]{2}{*}{$P$} \\
\hline & Mean & SD & Mean & SD & \\
\hline \multicolumn{6}{|c|}{ lodine insufficiency ${ }^{*}$} \\
\hline \multicolumn{6}{|c|}{ Yes } \\
\hline TSH (mIU/l) & 1.63 & 1.80 & 1.69 & 0.83 & $<0.001$ \\
\hline $\mathrm{FT}_{4}(\mathrm{ng} / \mathrm{dl})$ & $1 \cdot 17$ & 0.18 & 0.87 & 0.12 & $<0.001$ \\
\hline \multicolumn{6}{|l|}{ No } \\
\hline TSH (mIU/l) & 1.52 & $1 \cdot 13$ & 1.66 & 0.90 & 0.001 \\
\hline $\mathrm{FT}_{4}(\mathrm{ng} / \mathrm{dl})$ & 1.14 & 0.16 & 0.89 & 0.13 & $<0.001$ \\
\hline \multicolumn{6}{|c|}{ Positive thyroid antibodies } \\
\hline \multicolumn{6}{|c|}{ Yes } \\
\hline TSH (mIU/l) & 0.96 & 0.39 & 1.54 & 0.35 & 0.043 \\
\hline $\mathrm{FT}_{4}(\mathrm{ng} / \mathrm{dl})$ & $1 \cdot 11$ & 0.15 & 0.86 & 0.20 & 0.041 \\
\hline \multicolumn{6}{|l|}{ No } \\
\hline TSH (mIU/l) & 1.41 & 0.91 & 1.66 & 0.88 & $<0.001$ \\
\hline $\mathrm{FT}_{4}(\mathrm{ng} / \mathrm{dl})$ & $1 \cdot 19$ & 0.17 & 0.88 & 0.12 & $<0.001$ \\
\hline
\end{tabular}

$\mathrm{TSH}$, thyrotropin; $\mathrm{FT}_{4}$, free thyroxine.

*Urinary iodine concentration $<150 \mu \mathrm{g} / \mathrm{l}$. 
Table 4 Multiple linear regression with variables independently related to urinary iodine concentration $(\mathrm{UIC})^{\star}$, considering all collected samples ( $n$ 896), in women from the state of Rio de Janeiro, Brazil, September 2014-February 2017

\begin{tabular}{lrcrr}
\hline & \multicolumn{1}{c}{$\beta$} & \multicolumn{1}{c}{$95 \% \mathrm{Cl}$} & \multicolumn{1}{c}{$t$} & \multicolumn{1}{c}{$P$} \\
\hline Age (years) & -0.44 & $-0.71,-0.17$ & -3.17 & $<0.01$ \\
BMl (kg/m $\left.{ }^{2}\right)^{*}$ & 0.25 & $0.00,0.50$ & 1.97 & 0.05 \\
Multiparity & 0.15 & $0.02,0.28$ & 2.23 & 0.03 \\
\hline
\end{tabular}

Variables included in the model: age ${ }^{*}$, gestational week $^{*}$, serum thyrotropin $(\mathrm{mlU} / \mathrm{l})^{*}$ and free thyroxine $(\mathrm{ng} / \mathrm{dl})^{*}$ (at the time of UIC collection), iodine concentration in salt $(\mathrm{mg} / \mathrm{kg})^{*}$, first-trimester $\mathrm{BMI}^{*}$, smoking habit, positive serum thyroid antibodies (thyroperoxidase antibody and/or thyroglobulin antibody) and multiparity ( $\geq 3$ labours).

Only those correlations with $P \leq 0.100$ are shown in the table.

${ }^{*}$ After logarithmic transformation.

Evaluating possible independent risk factors associated with SCH during pregnancy, it was detected that those women with median UIC $\geq 250 \mu \mathrm{g} / \mathrm{l}$ during all gestational trimesters combined with at least one sample showing excessive UIC had 6.6 times more chance to have SCH diagnosis. However, thyroid autoimmunity was more prominently associated with this risk when added to the model. Smoking was also an independent factor positively associated with SCH (Table 7).

\section{Discussion}

To date, the present study is the first longitudinal one to evaluate iodine nutritional status and its association with thyroid function in pregnant Brazilian women. The main study finding indicated that iodine status remained adequate and stable from the beginning to the end of pregnancy. In addition, we observed an increased risk of SCH among women with excessive UIC.

Since $>90 \%$ of dietary iodine is excreted in the urine, median UIC has been used as the main method to assess the iodine status of a population ${ }^{(22)}$. For pregnant women, values between 150 and $249 \mu \mathrm{g} / 1$ indicate optimal iodine intake according to the WHO criteria ${ }^{(19)}$. In our sample, the overall median UIC was $216 \cdot 7 \mu \mathrm{g} / \mathrm{l}$. It varied within the normal range from $221.0 \mu \mathrm{g} / \mathrm{l}$ in the first trimester to
$208.0 \mu \mathrm{g} / \mathrm{l}$ in the third trimester, confirming our previous findings that the iodine nutritional status of pregnant women in Rio de Janeiro is classified as adequate ${ }^{(16)}$. Nevertheless, several authors have reported a significant drop in UIC with advancing pregnancy ${ }^{(23-25)}$. During the gestational period, increased hormone requirements and iodine losses alter the preconception steady-state. When pregnant women are exposed to insufficient iodine intake, body stores of this nutrient tend to fall gradually over time. In the second half of gestation as the fetal thyroid gland starts to function, part of the available iodine is transferred from maternal circulation to the fetal-placental unit, causing iodine deprivation to worsen in vulnerable individuals ${ }^{(7)}$.

In the present study, the small decrease in median UIC observed between the trimesters was not statistically significant. The same pattern was noticed in other iodinesufficient areas in Japan ${ }^{(26)}$, Mexico ${ }^{(27)}$, Sri Lanka ${ }^{(28)}$ and $\operatorname{Iran}^{(29)}$. This fact probably means that national salt iodization policies have achieved their goals in the studied location. As recently demonstrated, most brands of table salt used by pregnant women contained appropriate levels of iodine ${ }^{(16)}$. This is in line with a WHO recommendation that indicates that in regions with effective and sustained salt iodization ( $>90 \%$ of the households consuming iodized salt for at least two years) and optimal iodine nutrition, pregnant and lactating women do not need iodine supplementation ${ }^{(30)}$.

In our group of Brazilian women, regardless of insufficient urinary iodine or circulating thyroid antibodies, thyroid hormone levels varied significantly from the first to the third trimester even though they remained within the reference range. We believe that these changes were due to the well-known physiological adaptations of the thyroid gland to the demands of gestation ${ }^{(31)}$ as observed in other prospective studies conducted in iodine-sufficient regions ${ }^{(25,32)}$.

Our findings differ from those reported by Ferreira et al. and Mioto et al., who detected iodine deficiency in pregnant women from São Paulo(17,18). While the former

Table 5 Multiple linear regression with variables independently related to median urinary iodine concentration (UIC) ${ }^{*}$ per pregnant woman, considering all women (A) and excluding women taking levothyroxine and/or iodine supplements at the time of urinary sample collection (B), in women from the state of Rio de Janeiro, Brazil, September 2014-February 2017

\begin{tabular}{|c|c|c|c|c|c|c|c|c|}
\hline & & \\
\hline & \multicolumn{4}{|c|}{ All pregnant women ( $n$ 243) } & \multicolumn{4}{|c|}{ Excluding women taking levothyroxine or iodine supplements ( $n$ 212) } \\
\hline & $\beta$ & $95 \% \mathrm{Cl}$ & $t$ & $P$ & $\beta$ & $95 \% \mathrm{Cl}$ & $t$ & $P$ \\
\hline Age (years) ${ }^{\star}$ & -0.42 & $-0.77,-0.07$ & -2.34 & 0.02 & -0.43 & $-0.82,-0.29$ & $-2 \cdot 12$ & 0.03 \\
\hline BMI $\left(\mathrm{kg} / \mathrm{m}^{2}\right)^{*}$ & 0.29 & $-0.07,0.63$ & 1.61 & 0.10 & 0.22 & $-0.20,0.63$ & 1.03 & 0.09 \\
\hline $\mathrm{TSH}\left(\mathrm{mlU} / \mathrm{l}^{\star}\right.$ & - & - & - & - & 0.07 & $-0.01,0.14$ & 1.72 & 0.09 \\
\hline Multiparity & 0.17 & $0.00,0.34$ & 2.05 & 0.04 & 0.20 & $0.01,0.38$ & $2 \cdot 11$ & 0.03 \\
\hline
\end{tabular}

TSH, thyrotropin.

Variables included in the model: age ${ }^{*}$, mean $\mathrm{TSH}^{\star}$ during pregnancy, mean free thyroxine $(\mathrm{ng} / \mathrm{dl})^{\star}$ during pregnancy, iodine concentration in salt $(\mathrm{mg} / \mathrm{kg})^{\star}$, first-trimester $\mathrm{BMI}^{*}$, smoking habit, positive serum thyroid antibodies (thyroperoxidase antibody and/or thyroglobulin antibody) and multiparity ( $\geq 3$ labours). Only those correlations with $P \leq 0 \cdot 100$ are shown in the table.

${ }^{*}$ After logarithmic transformation. 
Table 6 Demographic characteristics and iodine status according to subclinical hypothyroidism (SCH) diagnosis at any time during pregnancy in women from the state of Rio de Janeiro, Brazil, September 2014-February 2017

\begin{tabular}{|c|c|c|c|c|c|}
\hline & \multicolumn{2}{|c|}{ With $\mathrm{SCH}$} & \multicolumn{2}{|c|}{ Without SCH } & \multirow[b]{2}{*}{$P$} \\
\hline & Mean or Median & SD or $\%$ & Mean or Median & SD or $\%$ & \\
\hline Age (years), mean and SD & $24 \cdot 0$ & 4.6 & $26 \cdot 9$ & 4.9 & 0.014 \\
\hline BMI $\left(\mathrm{kg} / \mathrm{m}^{2}\right)$, mean and SD & $23 \cdot 7$ & 4.5 & $25 \cdot 7$ & $5 \cdot 3$ & 0.070 \\
\hline ICS $(\mathrm{mg} / \mathrm{kg})$, mean and SD & $37 \cdot 1$ & $11 \cdot 1$ & $35 \cdot 2$ & $10 \cdot 3$ & 0.787 \\
\hline Smoking (\%) & & $16 \cdot 7$ & & 2.6 & $<0.01$ \\
\hline Multiparity* (\%) & & 0.0 & & $23 \cdot 3$ & 0.060 \\
\hline Thyroid antibodies $\ddagger$ (\%) & & 41.7 & & $7 \cdot 0$ & $<0.01$ \\
\hline \multicolumn{6}{|l|}{ UIC } \\
\hline Median $(\mu \mathrm{g} / \mathrm{l})$ & 267 & & 224 & & 0.601 \\
\hline Any UIC $\geq 500 \mu \mathrm{g} / \mathrm{I}(\%)$ & & 41.7 & & $17 \cdot 3$ & 0.034 \\
\hline Median UIC $\geq 250 \mu \mathrm{g} / \mathrm{l}(\%)$ & & $25 \cdot 0$ & & 13.0 & 0.236 \\
\hline Median UIC $\geq 500 \mu \mathrm{g} / \mathrm{l}(\%)$ & & 0.0 & & $2 \cdot 2$ & 0.775 \\
\hline Any $U I C<150 \mu \mathrm{g} / \mathrm{I}(\%)$ & & $75 \cdot 0$ & & $55 . \overline{4}$ & 0.182 \\
\hline Median UIC < $150 \mu \mathrm{g} / \mathrm{I}(\%)$ & & 8.3 & & $17 \cdot 3$ & 0.418 \\
\hline
\end{tabular}

ICS, iodine concentration in salt; UIC, urinary iodine concentration.

$\mathrm{SCH}$ defined as thyrotropin $\geq 3.8 \mathrm{mlU} / \mathrm{l}$.

${ }^{*}$ Three or more labours.

$\ddagger$ Positive serum thyroperoxidase antibody and/or thyroglobulin antibody.

Table 7 Multivariate analysis showing independent factors associated with subclinical hypothyroidism (SCH) diagnosis during pregnancy in women from the state of Rio de Janeiro, Brazil, September 2014-February 2017

\begin{tabular}{|c|c|c|c|c|c|c|c|}
\hline & \multicolumn{4}{|c|}{ Step $1^{*}$} & \multicolumn{3}{|c|}{ Step $2 \dagger$} \\
\hline & OR & 95 & $\% \mathrm{Cl}$ & $P$ & OR & $95 \% \mathrm{Cl}$ & $P$ \\
\hline Any $U I C \geq 500 \mu \mathrm{g} / \mathrm{I}+$ median $\mathrm{UIC} \geq 250 \mu \mathrm{g} / \mathrm{l}$ & $6 \cdot 6$ & $1 \cdot 2$ & $37 \cdot 4$ & 0.033 & 3.7 & $0.6,25.4$ & 0.173 \\
\hline Age (years) & 0.8 & 0.7 & 1.0 & 0.100 & 0.8 & $0.7,1.0$ & 0.066 \\
\hline Smoking & $213 \cdot 0$ & $7 \cdot 2$ & $6000 \cdot 0$ & 0.002 & $215 \cdot 0$ & $5 \cdot 4,8500 \cdot 0$ & 0.004 \\
\hline Positive serum thyroid antibodies & - & & - & - & $7 \cdot 2$ & $0 \cdot 9,56 \cdot 2$ & 0.056 \\
\hline
\end{tabular}

UIC, urinary iodine concentration.

$\mathrm{SCH}$ defined as thyrotropin $\geq 3.8 \mathrm{mIU} / \mathrm{l}$.

*Variables included in the model: age, BMI $\left(\mathrm{kg} / \mathrm{m}^{2}\right)$, multiparity ( $\geq 3$ labours), smoking, iodine supplement use, insufficient iodine content in table salt, any UIC $\geq 500 \mu \mathrm{g} / \mathrm{I}+$ median UIC $\geq 250 \mu \mathrm{g} / \mathrm{l}$.

†Adding positive serum thyroid antibodies to the model (thyroperoxidase antibody and/or thyroglobulin antibody).

studied only pregnant women in the first trimester, the latter included women during the three trimesters of gestation. Both studies raised great concerns about the adequacy of the iodine supply of pregnant women in the country, especially considering that their data were collected before the new Brazilian governmental determinations regarding the reduction of iodine concentrations in table salt from $20-60$ to $15-45 \mathrm{mg} / \mathrm{kg}^{(21)}$. However, the present study and the recent report by Saraiva et al. ${ }^{(16)}$ corroborate that the results obtained in São Paulo should not be extrapolated to the entire population of pregnant women in Brazil, a country with continental proportions and different profiles of iodine consumption, even in a single region. Compared with previous Brazilian studies, ours was the only one designed to evaluate the changes in iodine nutrition during the course of gestation because we measured UIC in the first and third trimesters in the same participant, while all other studies were done in a crosssectional manner ${ }^{(16-18,33,34)}$. In addition, considering the great variability of UIC, we sought to minimize this effect by analysing multiple urine samples from each pregnant woman. Thus, we could also examine the associations between UIC and thyroid function using the median of each woman's samples, which more accurately reflected their iodine status rather than only a single measurement as used in most studies.

Maternal UIC was above the normal range $(\geq 250 \mu / 1)$ in $>40 \%$ of the analysed samples and excessive $(\geq 500 \mu / 1)$ in $6.4 \%$ of the samples. Women with median UIC $\geq 250 \mu \mathrm{g} / 1$ and at least one sample showing excessive UIC had a 6.6fold increased risk of presenting $\mathrm{SCH}$ at some point during gestation. These data reinforce that although all efforts must be made to eliminate iodine deficiency and its serious consequences, excessive iodine intake during pregnancy should also be avoided. It is well established that high iodine exposure can cause hyper- or hypothyroidism, especially in those with past or present thyroid abnormalities. This occurs because, in a damaged thyroid gland, the normal down-regulation of iodine transport into the thyroid cells may not occur ${ }^{(12)}$. Besides, the ability to fully 'escape' from the transient inhibition of thyroid hormone synthesis after a large iodine load, known as the acute Wolff-Chaikoff effect, does not mature until 36 weeks of gestation. In this setting, fetal hypothyroidism may 
develop even if maternal thyroid function is maintained $^{(35)}$. A cross-sectional study involving 7190 pregnant women from an iodine-sufficient area in China also found an increased risk of SCH in women with UIC $\geq 250 \mu \mathrm{g} / \mathrm{l}^{(36)}$. Those with UIC $\geq 500 \mu \mathrm{g} / \mathrm{l}$ showed an additional higher risk for isolated hypothyroxinaemia. The occurrence of $\mathrm{SCH}$ during gestation contributes to an increased rate of adverse obstetric and birth outcomes, including pregnancy loss, preterm delivery and placental abruption in addition to neurodevelopmental deficits in the offspring ${ }^{(37)}$. Furthermore, there is also evidence that iodine excess can be considered an environmental risk factor for autoimmune thyroid disease ${ }^{(38)}$.

Another finding that deserves attention was the median UIC $(262 \cdot 1 \mu \mathrm{g} / \mathrm{l})$ among women who were using iodinecontaining supplements in the third-trimester evaluation; although there was no statistically significant difference between their UIC and those in the rest of the group, their iodine status was classified in a different range and considered more than adequate according to the WHO criteria $^{(19)}$. Excessive UIC was also more frequently observed among these women. For these reasons, we advise that indiscriminate iodine supplementation during pregnancy should be carefully balanced against the risk of iodine excess.

Not only the excessive iodine intake and the presence of circulating thyroid antibodies were associated with $\mathrm{SCH}$, but also smoking habits. This habit seems to induce changes in thyroid function tests. The role of smoking in Hashimoto's thyroiditis is not as well established as in Graves' disease ${ }^{(39)}$. Although there is evidence that smoking is associated with a lower prevalence of hypothyroidism and circulating thyroid antibodies ${ }^{(40)}$, these findings contrast with another study that reported increased risk of hypothyroidism in smokers with Hashimoto's thyroiditis ${ }^{(41)}$.

When examining the possible correlations between all collected UIC and clinical parameters, we found that older women tended to have lower levels of urinary iodine similar to Saraiva et ll $^{\left({ }^{16)}\right.}$. Age appears to influence iodine status in non-pregnant adults, but studies in adult populations are divergent ${ }^{(42-45)}$. Several authors also reported a decrease in UIC with advancing age ${ }^{(42-44)}$. The reasons for this are unknown but may be related to dietary variations, physiological requirements and age-related changes in glomerular filtration rate. These possible causal factors should be further investigated specifically in pregnant women. Regarding parity and BMI, the opposite was observed. As previously shown by us, women with more children and women with greater BMI had higher levels of $\mathrm{UIC}^{(16)}$. In a recent study conducted by De Zoysa et al., parity and initial BMI were also significantly correlated with the third-trimester UIC ${ }^{(46)}$. However, while UIC and BMI correlated positively, UIC and parity correlated negatively.
One limitation of our study was the non-inclusion of patients aged $>35$ years. As this cohort is being followed for the evaluation of maternal and fetal outcomes, advanced age could act as a confounding factor. Median UIC might have been lower if older women were included. In addition, we recruited only healthy pregnant women assisted by the public health system and there may be differences in education levels, social class and nutritional status compared with the general population of the state.

\section{Conclusions}

Pregnant women in the studied geographical location had adequate UIC during the first and third trimesters and were considered to have appropriate iodine nutrition. The variations in TSH and $\mathrm{FT}_{4}$ levels could not be attributed to insufficient iodine supply or circulating thyroid antibodies. Excessive UIC and smoking were associated with an increased risk for SCH development. Therefore, generalized iodine supplementation in Brazil should not be implemented because of the risks associated with excessive iodine exposure.

\section{Acknowledgements}

Acknowledgements: The authors would like to thank the Brazilian Ministry of Health, the National Research Council (CNPq) and the Thyroid Department of the Brazilian Society of Endocrinology and Metabolism (SBEM), which encouraged this work. They are also grateful to Mischelle P Santos and the Institute of Nutrition of the State University of Rio de Janeiro for the analysis performed. Financial support: The study was financially supported by Fundação Carlos Chagas Filho de Amparo à Pesquisa do Estado do Rio de Janeiro (FAPERJ) (grant number E-26/202.143/2015). FAPERJ had no role in the design, analysis or writing of this article. Conflict of interest: None. Authorship: C.M.C., M.V., P.F.S.T., T.M.B.L.B., D.A.S., N.A.O.S.M. and A.S. designed the study and formulated the research questions; C.M.C., T.M.B.L.B., D.A.S., N.A.M., A.S. and L.N.G. conducted the study; P.F.S.T. and C.M.C. analysed the data. The manuscript was written by C.M.C. and reviewed by M.V. and P.F.S.T. All authors read and approved the final version. Ethics of buman subject participation: This study was conducted according to the guidelines laid down in the Declaration of Helsinki and all procedures involving human subjects were approved by the local ethics committee (CAAE: 22546213.0.0000.5275). Written informed consent was obtained from all participants. 


\section{References}

1. Zimmermann MB (2009) Iodine deficiency. Endocr Rev 30 , 376-408.

2. Zimmermann MB (2007) The adverse effects of mildto-moderate iodine deficiency during pregnancy and childhood: a review. Thyroid 17, 829-835.

3. Taylor PN, Okosieme OE, Dayan CM et al. (2014) Therapy of endocrine disease: impact of iodine supplementation in mild-to-moderate iodine deficiency: systematic review and meta-analysis. Eur J Endocrinol 170, 1-15.

4. Gowachirapant S, Winichagoon P, Wyss L et al. (2009) Urinary iodine concentrations indicate iodine deficiency in pregnant Thai women but iodine sufficiency in their schoolaged children. J Nutr 139, 1169-1172.

5. Zimmermann MB (2010) Symposium on 'Geographical and geological influences on nutrition' - iodine deficiency in industrialised countries. Proc Nutr Soc 69, 133-143.

6. Pearce EN, Andersson M \& Zimmermann MB (2013) Global iodine nutrition: where do we stand in 2013? Thyroid $\mathbf{2 3}$, 523-528.

7. Glinoer D (2004) The regulation of thyroid function during normal pregnancy: importance of the iodine nutrition status. Best Pract Res Clin Endocrinol Metab 18, 133-152.

8. Alexander EK, Pearce EN, Brent GA et al. (2017) 2017 guidelines of the American Thyroid Association for the diagnosis and management of thyroid disease during pregnancy and the postpartum. Thyroid 27, 315-389.

9. De Groot L, Abalovich M, Alexander EK et al. (2012) Management of thyroid dysfunction during pregnancy and postpartum: an Endocrine Society clinical practice guideline. J Clin Endocrinol Metab 97, 2543-2565.

10. Lazarus J, Brown RS, Daumerie C et al. (2014) 2014 European Thyroid Association guidelines for the management of subclinical hypothyroidism in pregnancy and in children. Eur Thyroid J 3, 76-94.

11. National Health and Medical Research Council (2010) NHMRC Public Statement: iodine supplementation for pregnant and breastfeeding women. https://www.nhmrc. gov.au/guidelines-publications/new 45 (accessed July 2018).

12. Pearce EN, Lazarus JH, Moreno-Reyes R et al. (2016) Consequences of iodine deficiency and excess in pregnant women: an overview of current knowns and unknowns. $\mathrm{Am}$ J Clin Nutr 104, Suppl. 3, S918-S923.

13. Serrano-Nascimento C, Salgueiro RB, Vitzel KF et al. (2017) Iodine excess exposure during pregnancy and lactation impairs maternal thyroid function in rats. Endocr Connect $\mathbf{6}$, 510-521.

14. Rebagliato M, Murcia M, Espada M et al. (2010) Iodine intake and maternal thyroid function during pregnancy. Epidemiology 21, 62-69.

15. Velasco I, Carreira M, Santiago P et al. (2009) Effect of iodine prophylaxis during pregnancy on neurocognitive development of children during the first two years of life. $J$ Clin Endocrinol Metab 94, 3234-3241.

16. Saraiva DA, Morais NA, Corcino CM et al. (2018) Iodine status of pregnant women from a coastal Brazilian state after the reduction in recommended iodine concentration in table salt according to governmental requirements. Nutrition $\mathbf{5 3}$, 109-114.

17. Ferreira SM, Navarro AM, Magalhães PK et al. (2014) Iodine insufficiency in pregnant women from the State of São Paulo. Arq Bras Endocrinol Metabol 58, 282-287.

18. Mioto VC, Monteiro AC, Camargo RY et al. (2018) High prevalence of iodine deficiency in pregnant women living in adequate iodine area. Endocr Connect 7, 762-767.

19. World Health Organization, UNICEF \& International Council for Control of Iodine Deficiency Disorders (2007) Assessment of Iodine Deficiency Disorders and Monitoring Their
Elimination: A Guide for Programme Managers, 3rd ed. Geneva: WHO.

20. Instituto Adolfo Lutz (2008) Determinação de iodo adicionado na forma de iodeto. In Métodos Físico-Químicos para Análise de Alimentos, 4th ed., pp. 720-721. São Paulo: Instituto Adolfo Lutz.

21. Agência Nacional de Vigilância Sanitária (2013) RDC No 23, de 24 de abril de 2013. http://bvsms.saude.gov.br/bvs/ saudelegis/anvisa/2013/res0023_23_04_2013.html （accessed July 2018).

22. Zimmermann MB \& Andersson M (2012) Assessment of iodine nutrition in populations: past, present, and future. Nutr Rev 70, 553-570.

23. Amouzegar A, Khazan M, Hedayati M et al. (2014) An assessment of the iodine status and the correlation between iodine nutrition and thyroid function during pregnancy in an iodine sufficient area. Eur J Clin Nutr 68, 397-400.

24. Ainy E, Ordookhani A, Hedayati M et al. (2007) Assessment of intertrimester and seasonal variations of urinary iodine concentration during pregnancy in an iodine-replete area. Clin Endocrinol (Oxf) 67, 577-581.

25. Fuse Y, Shishiba Y \& Irie M (2013) Gestational changes of thyroid function and urinary iodine in thyroid antibodynegative Japanese women. Endocr J 60, 1095-1106.

26. Fuse Y, Ohashi T, Yamaguchi S et al. (2011) Iodine status of pregnant and postpartum Japanese women: effect of iodine intake on maternal and neonatal thyroid function in an iodine-sufficient area. J Clin Endocrinol Metab 96, 3846-3854.

27. García-Solís P, Solís-S JC, García-Gaytán AC et al. (2011) Iodine nutrition status in pregnant women in Mexico. Thyroid 21, 1367-1371.

28. Smyth PP (1999) Variation in iodine handling during normal pregnancy. Thyroid 9, 637-642.

29. Rezvanian H, Aminorroaya A, Majlesi M et al. (2002) Thyroid size and iodine intake in iodine-repleted pregnant women in Isfahan, Iran. Endocr Pract 8, 23-28.

30. Andersson M, De Benoist B, Delange F et al. (2007) Prevention and control of iodine deficiency in pregnant and lactating women and in children less than 2-years-old: conclusions and recommendations of the Technical Consultation. Public Health Nutr 10, 1606-1611.

31. Glinoer D (1997) The regulation of thyroid function in pregnancy pathways of endocrine adaption from physiology to pathology. Endocr Rev 18, 404-433.

32. Fister P, Gaberscek S, Zaletel K et al. (2011) Thyroid function in the third trimester of pregnancy and after delivery in an area of adequate iodine intake. Int J Gynecol Obstet 112, $52-55$.

33. Barca MF, Knobel M, Tomimori E et al. (2001) Aspectos ultra-sonográficos e prevalência da tireoidite pós-parto em gestantes sem disfunção tireóidea atendidas em hospital público de São Paulo. Arq Bras Endocrinol Metab 45, 180-189.

34. Soares R, Vanacor R, Manica D et al. (2008) Thyroid volume is associated with family history of thyroid disease in pregnant women with adequate iodine intake: a crosssectional study in southern Brazil. J Endocrinol Invest 31, 614-617.

35. Connelly KJ, Boston BA, Pearce EN et al. (2012) Congenital hypothyroidism caused by excess prenatal maternal iodine ingestion. J Pediatr 161, 760-762.

36. Shi X, Han C, Li C et al. (2015) Optimal and safe upper limits of iodine intake for early pregnancy in iodine-sufficient regions: a cross-sectional study of 7190 pregnant women in China. J Clin Endocrinol Metab 100, 1630-1638.

37. Chan S \& Boelaert K (2015) Optimal management of hypothyroidism, hypothyroxinaemia and euthyroid TPO antibody positivity preconception and in pregnancy. Clin Endocrinol (Oxf) 82, 313-326. 
38. Luo Y, Kawashima A, Ishido Y et al. (2014) Iodine excess as an environmental risk factor for autoimmune thyroid disease. Int J Mol Sci 15, 12895-12912.

39. Sawicka-Gutaj N, Gutaj P, Sowiński J et al. (2014) Influence of cigarette smoking on thyroid gland - an update. Endokrynol Pol 65, 54-62.

40. Wiersinga WM (2013) Smoking and thyroid. Clin Endocrinol (Oxf) 79, 145-151.

41. Fukata S, Kuma K \& Sugawara M (1996) Relationship between cigarette smoking and hypothyroidism in patients with Hashimoto's thyroiditis. J Endocrinol Invest 19, 607-612.

42. Als C, Keller A, Minder C et al. (2000) Age- and genderdependent urinary iodine concentrations in an areacovering population sample from the Bernese region in Switzerland. Eur J Endocrinol 143, 629-637.
43. Zamrazil V, Bilek R, Cerovska J et al. (2004) The elimination of iodine deficiency in the Czech Republic: the steps toward success. Thyroid 14, 49-56.

44. Tang K-T, Wang F-F, Pan W-H et al. (2016) Iodine status of adults in Taiwan 2005-2008, 5 years after the cessation of mandatory salt iodization. J Formos Med Assoc 115, 645-651.

45. Haddow JE, McClain MR, Palomaki GE et al. (2007) Urine iodine measurements, creatinine adjustment, and thyroid deficiency in an adult United States population. J Clin Endocrinol Metab 92, 1019-1022.

46. De Zoysa E, Hettiarachchi M \& Liyanage C (2016) Urinary iodine and thyroid determinants in pregnancy: a follow up study in Sri Lanka. BMC Pregnancy Childbirth 16, 303. 